\title{
Effects of peatland drainage management on peak flows
}

\author{
C. E. Ballard ${ }^{1,2}$, N. McIntyre ${ }^{1}$, and H. S. Wheater ${ }^{1,3}$ \\ ${ }^{1}$ Department of Civil and Environmental Engineering, Imperial College London, London SW7 2AZ, UK \\ ${ }^{2}$ Aqualinc Research Ltd, 11 Deans Avenue, Christchurch, 8011, New Zealand \\ ${ }^{3}$ Canada Excellence Research Chair in Water Security, University of Saskatchewan, National Hydrology Research Centre, \\ 11 Innovation Boulevard, Saskatoon, Saskatchewan S7N 3H5, Canada \\ Correspondence to: C. E. Ballard (c.ballard@aqualinc.co.nz)
}

Received: 19 January 2011 - Published in Hydrol. Earth Syst. Sci. Discuss.: 6 July 2011

Revised: 27 June 2012 - Accepted: 28 June 2012 - Published: 24 July 2012

\begin{abstract}
Open ditch drainage has historically been a common land management practice in upland blanket peats, particularly in the UK. However, peatland drainage is now generally considered to have adverse effects on the upland environment, including increased peak flows. As a result, drain blocking has become a common management strategy in the UK over recent years, although there is only anecdotal evidence to suggest that this might decrease peak flows. The change in the hydrological regime associated with the drainage of blanket peat and the subsequent blocking of drains is poorly understood, therefore a new physics-based model has been developed that allows the exploration of the associated hydrological processes. A series of simulations is used to explore the response of intact, drained and blocked drain sites at field scales. While drainage is generally found to increase peak flows, the effect of drain blocking appears to be dependent on local conditions, sometimes decreasing and sometimes increasing peak flows. Based on insights from these simulations we identify steep smooth drains as those that would experience the greatest reduction in field-scale peak flows if blocked and recommend that future targeted field studies should be focused on examining surface runoff characteristics.
\end{abstract}

\section{Introduction}

In the UK there are approximately 2.9 Mha of upland peatlands, with the majority of this present as blanket peatlands (Holden et al., 2004). These areas constitute approximately $15 \%$ of the blanket peatlands globally (Milne and Brown, 1997). Blanket peat deposits are typically found draped over gently-rolling terrain in areas with a cool climate, high rainfall and impeded substrate drainage. These conditions allow peat formation, which occurs when organic material decomposes slowly due to anaerobic conditions associated with waterlogging (Allaby, 2008). Although historically considered to be regions of low value, the importance of peatlands in terms of carbon sequestration, ecological value and water supply is now increasingly recognised (Bonn et al., 2009). The management of peatlands has therefore become a topic of interest for a number of different stakeholders.

Although peat itself consists of almost $90 \%$ water, much of this water is tightly bound in the decaying organic material. As a consequence, the sponge analogy of peatlands is inaccurate, as although they hold a significant volume of water, its movement is heavily restricted, and these areas have very little ability to absorb and store additional water. As a consequence, water tables are observed to be within tens of centimetres from the surface throughout the year (Evans et al., 1999), and the runoff from these regions is characteristically flashy.

In the UK, almost half of the upland peatlands were drained during a period of agricultural intensification in the 1960s and 1970s (Milne and Brown, 1997). This was typically done via open ditch drainage, with drains across the surface angled between the site slope and the site contours. The intention was that water tables would be reduced in order to encourage vegetation cover more suitable for livestock grazing (Stewart and Lance, 1983). Open ditch drainage changes the hydrological response by (1) creating more storage in the subsurface and (2) by providing a rapid conduit for runoff. Process (1) tends to reduce the flashiness of system response while process (2) increases it; which process is dominant is 
likely to be dependent on a number of site specific characteristics. In the case of drained blanket peatlands, drainage generally causes only localised drawdown of the water table (Robinson, 1986; Stewart and Lance, 1983), and in most reported cases, the runoff response is found to have reduced times to peak and increased peak flows (Ahti, 1980; Conway and Millar, 1960; Holden et al., 2006; Robinson, 1986; Stewart and Lance, 1991); the influence of the faster conveyance generally outweighs any benefits of increased storage in drained peatlands in terms of controlling peak flows.

Not only does peatland drainage cause potentially detrimental changes in the runoff response, but the practice has also been observed to lead to greater erosion in these sensitive environments (Holden et al., 2007), to changes in local ecosystems and to increases in concentrations of dissolved organic carbon (DOC) in the runoff (Worrall et al., 2007b). Owing to the numerous problems observed with drainage, activities are now underway in the UK to attempt to restore these upland environments (Armstrong et al., 2009; Ewen et al., 2010; Holden et al., 2004; Wilson et al., 2010). Beginning in the 1980s, a programme of drain blocking in peatlands was started.

While there is some evidence that drain blocking has benefits for ecosystem services (such as the restoration of habitats and carbon sequestration; e.g. Wallage et al., 2006; Worrall et al., 2007b) the impact on peak flows has not been determined conclusively. This is largely due to a lack of suitable data; most experiments examining the impacts of drain blocking have focused on changes in water table levels (e.g. Armstrong et al., 2010; Price, 2003; Wilson et al., 2010), but even these studies are limited in number. There are also methodological challenges associated with the measurement of flow following drain blocking; cases have been noted where the occurrence of drain flow is reduced by up to as much as $70 \%$ following drain blocking (Worrall et al., 2007a) but this is just within the drainage channels themselves and not necessarily at a location that also measures water that might spill downslope from the blocked drains. Other studies have shown that water tables have become closer to the surface following drain blocking (Price, 2003; Wilson et al., 2010), and increased overland flow has been observed immediately after blocking (Shantz and Price, 2006). Although there are an increasing number of studies of blocked drains within the UK, the efficacy of restoration is still unclear due to strong influences of local conditions and lack of pre-drain blocking data for comparison (Wilson et al., 2010).

Complete infilling of drains is uncommon, owing to the expense associated with the practice, therefore drains are typically blocked at intervals along their course (Armstrong et al., 2009). There are many different methods of doing this, including peat dams, heather bales, plastic piling, corrugated Perspex, plywood, wooden planks, stones or some combination of the above (Armstrong et al., 2009). With the exception of heather bales, all practices aim to create a water-tight seal at a section or over a short length of the drain. Although
Table 1. Predicted direction of change of parameter values following drainage management change.

\begin{tabular}{lcc}
\hline Parameter name & Drainage & Drain blocking \\
\hline Drain roughness & $\downarrow \uparrow$ & $\uparrow$ \\
Surface roughness & $\uparrow$ & $\downarrow$ \\
Acrotelm thickness & $\uparrow$ & $\downarrow$ \\
Acrotelm hydraulic conductivity & $\downarrow \uparrow$ & $\downarrow \uparrow$ \\
Catotelm hydraulic conductivity & $\downarrow \uparrow$ & $\downarrow \uparrow$ \\
\hline
\end{tabular}

plastic piling is generally found to be the most effective drain blocking technique, peat dams are the most commonly implemented, owing to reasons of cost, aesthetics and preferences of the land managers. When implemented effectively, water from behind the block diffuses over the downslope peat surface (Armstrong et al., 2009).

The change in hydrological regime associated with drainage management change is likely to have impacts on plant species and soil structure, and consequently on the predicted change in runoff response. For example, observations have been made that following drainage, the prevalence of hydraulically rough species (such as Sphagnum) is reduced (Coulson et al., 1990) and it is assumed that following drain blocking that these species may also begin to recolonise. Following drainage, drains may become hydraulically smoother due to erosion processes, or rougher if plants colonise the drains. Soil structural changes are also observed with changes in peatland management (Ramchunder et al., 2009). Peatland drainage can be associated with both consolidation of peat as it dries leading to subsidence (Holden et al., 2004), as well increased macropore activity, propensity for desiccation cracking and soil pipe development (Holden et al., 2006). The difference between the catotelm and acrotelm are primarily related to the fact that the catotelm is almost always saturated leading to anoxic conditions (Evans et al., 1999), therefore changes in water table heights may alter the relative thickness of these two layers. The recovery of these altered properties following drain blocking is unclear, largely due to a lack of experimental evidence to measure properties both pre and post-blocking (Wilson et al., 2010). The evidence of direction of change of physical properties following drainage management change is summarised in Table 1.

Although some anecdotal evidence is available, it is unclear how local conditions affect the changes that occur in the hydrological regime following drain blocking. Given the extent of peatland drain blocking currently occurring in the $\mathrm{UK}$, there is a need for a predictive tool, or at least some best practice guidelines, to support land managers in the selection and prioritisation of which peatland drains to block and also to assess if drain blocking can really restore peatlands to a near-intact hydrological condition. With limited monitoring data, physics-based hydrological modelling is a tool that can be used to explore some of these changes and 
test drainage management scenarios. In this paper, an existing drained peatland model is adapted in order to represent the hydrological effects of drain blocking at the field scale. The original and adapted models are used to explore the effects of peatland drainage management (intact, drained and blocked drains) under varying site conditions. The results of the models are used to

- Evaluate difference in peak flows of intact, drainage and drain blocked sites.

- Explore the site factors which potentially control these differences.

- Identify field data that could improve the model structure and assist in the reduction of prediction uncertainty.

\section{Model development}

The current research develops upon the field scale $(200 \mathrm{~m}$ by $200 \mathrm{~m}$ ) peatland model of Ballard et al. (2011). This is a physics-based model, where minor processes are either excluded or treated in a simplified manner in order to avoid over-parameterisation, and where the complexity of process representations reflects the availability of information for conceptualisation and parameterisation. The model uses the Boussinesq equation to describe subsurface flows, and the kinematic wave equation to describe overland and channel flow. Overland flow roughness is parameterised based on information in Holden et al. (2008) for a range of typical peatland vegetation types. A depth-averaged hydraulic conductivity is used in order to represent the presence of a higher hydraulic conductivity upper layer (acrotelm) over a lower hydraulic conductivity deeper layer (catotelm). An impermeable lower boundary is assumed to be present at the depth of the drain beds. The partial differential equations describing the variation of flow depths with time, for each of the one-dimensional models, are discretised in space using finite differences. The resulting ordinary differential equations are then integrated in Matlab using the ode15s stiff ordinary differential equation solver (Shampine and Reichelt, 1997; Shampine et al., 1999). The solver uses an adaptive time grid, which limits the numerical error associated with each time step to within a user defined tolerance.

The model was tested by Ballard et al. (2011) against data from a drained, unblocked site in the Yorkshire Dales and had good agreement with observations, particularly for higher flows. During the validation period those parameter sets that were considered to be "behavioural" led to an average RMSE across six boreholes of 0.06 to $0.07 \mathrm{~m}$ and RMSE for the flow predictions of 0.07 to $0.081 \mathrm{~s}^{-1}$ (the maximum observed flow was approximately $31 \mathrm{~s}^{-1}$ ). The performance of the model in predicting the responses demonstrated in Ballard et al. (2011) provides some extra confidence in the otherwise a priori model structure. All of the model parameters were identifiable, suggesting that the model is not over parameterised and that all the parameters have some sort of measurable influence on the predicted model response. Significantly, it was possible to calibrate the model using locally measured physical parameters or ranges that were restricted from measured values in the literature. Applying the chosen performance criteria and considering the ranges of parameter values perceived to be possible a priori for this site, no evidence was found to suggest that the parameters are inconsistent with their true (measurable) physical meanings. This provides support for using this model structure in other peatland sites in speculative simulations where there is no supporting data, but some knowledge about the range of potential physical properties. This model can also be used to describe intact peatlands by omitting all but the outlet drain. For the analysis reported in this paper, the model was extended to include the option of drain blocking.

Peatland drain blocking procedures vary at different sites, but current best practice is to construct a series of "dams", such that during significant storm events the water overflows from the drain and downslope across the vegetated peat surface, rather than overtopping the dams and continuing down the drain (Armstrong et al., 2009). A conceptualisation of this process is shown in Fig. 1. In Fig. 1 (and Fig. 2), the $\mathrm{z}$ direction is vertical, the $\mathrm{y}$ direction is along the contours (which are assumed to be parallel), the $\mathrm{x}$ direction is the orthogonal downslope direction, and $\mathrm{x}^{\prime}$ is the direction of the sloping ground surface. The drained peatland model was adapted to incorporate this conceptualisation by representing the blocked drains as a series of reservoirs. The dams are assumed to be infinitely thin, which leads to a slight overestimation of the storage volume of each reservoir. Once the reservoirs are full, water is assumed to spill downslope (in the $\mathrm{x}^{\prime}$ direction): Fig. $1 \mathrm{~b}$ demonstrates these flow paths. Except in the special case that the drain bed has zero slope, the spill is concentrated near the dams, and spill volumes vary along the length of the reservoir; this behaviour has been observed in the field (e.g. Geris, 2012).

In the original peatland model of Ballard et al. (2011), a representative "soil section" is modelled between two drains using a number of independent "soil slices" (Fig. 2a). Each "soil slice" consists of coupled one-dimensional models of subsurface and overland flows. Flow depths in the drain act as the boundary conditions for the "soil slices". Flows are accumulated along the length of the drain and routed to the collector drain (the drain running in the $\mathrm{x}^{\prime}$ direction on the left of the block diagrams in Figs. 1 and 2) using a kinematic wave equation. This representation is not valid in the case of blocked drains, because the water from the blocked drains cascades downslope overland in the $\mathrm{x}^{\prime}$ direction; therefore, "soil sections" (as shown in Fig. 2a) cannot be assumed to be independent of one another. For the blocked scenarios calculations are made for a "soil section" that is as long as the site and one reservoir wide (Fig. 2b), and which consists of a number of "sub-sections" between reservoirs. The flow input to each "sub-section" includes the cumulative flow from all 
(a)

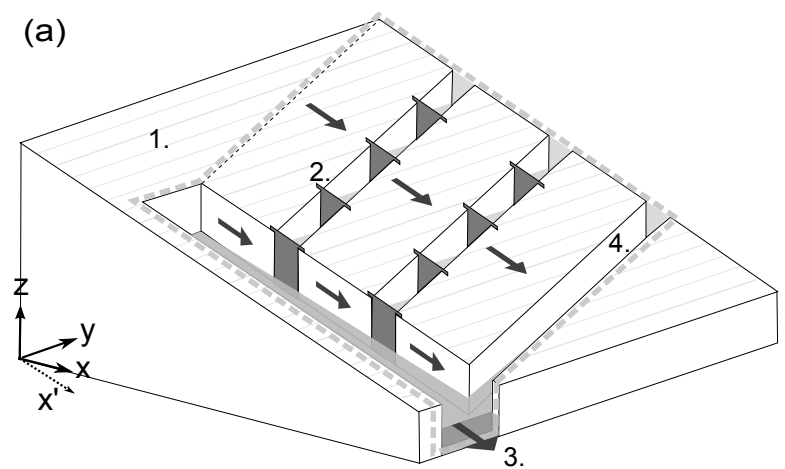

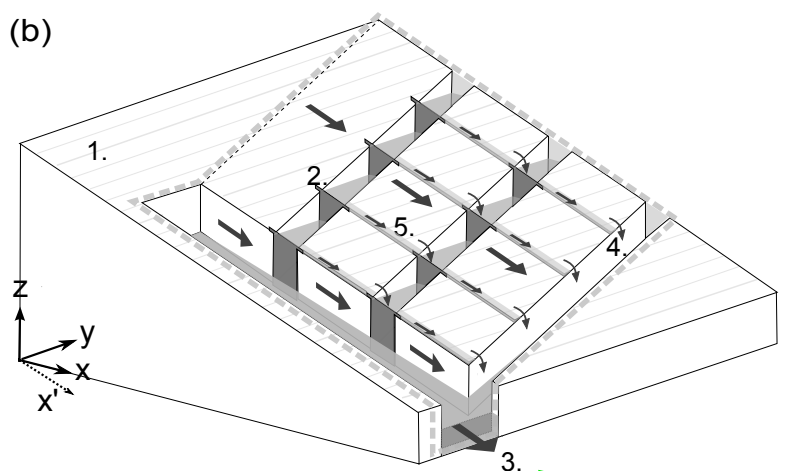

Fig. 1. Conceptualisation of flow paths in a blocked drain peatland; (a) as the blocked drains are filling and (b) as the blocked drains are overflowing. Annotated items: (1) hillslope contours, (2) drain dams, (3) field outlet, (4) unblocked drain, (5) overflow from the blocked drains.

upslope spilling reservoirs as well as the rainfall directly on that "sub-section". For the purpose of simulating the variability of the reservoir water level in the y-direction, and hence the boundary conditions for the "sub-sections", each "sub-section" is discretised into "soil slices" (see Fig. 2b). The flow is then accumulated in the most downslope (unblocked) drain, where the water is then routed to the field outlet (Fig. 2b).

Both the drained and blocked drain models have a number of limitations, largely due to lack of data for model verification and due to assumptions required for model simplicity. In the blocked model, there is no mechanism for flow around the blocks into the downstream reservoirs; therefore, the model assumes ideal drain blocking. All overland flow is assumed to run downslope in the $\mathrm{x}^{\prime}$ direction. Because the flow spilling out of the drains is concentrated behind the dams, thus producing a cross-slope (y-direction) energy gradient due the differences in flow depths, the validity of the assumption that the flow gradients follow the direction of the hillslope is reduced. Likewise, across slope flow within the peat soil blocks has not been accounted for. However, this is likely to be significant only on very shallow slopes. Both models apply only to shallow open drains ( $<1 \mathrm{~m}$ deep); the needs for remediation for large gullies are different from those of typical peatland drains (Armstrong et al., 2009) and are not covered in this study. Although the original model was tested by Ballard et al. (2011) for unblocked drains, the blocked drain model was not validated against field observations, as no suitable datasets (including field outlet flows) appear to be published or readily available.

\section{Intact, drained and blocked drain scenarios}

Simulations were performed using the intact, drained and blocked drain models to investigate changes in flow response associated with drainage management. Because there is variability in peatland site properties, a Monte Carlo analysis framework was employed to investigate the flow responses from peatlands with a range of hydrological properties. The parameter ranges in Table 2 were selected to represent typical ranges of physical and hydrological properties observed in blanket peatlands in the UK. The drain angle is defined as the angle between the drain and the contours of the site (as measured in the horizontal plane). Along with the site slope, the drain angle governs the drain slope and the geometry of the reservoirs in the blocked drains. As nationwide values for slope and drain angle in peatlands were not readily available, ranges were evaluated from DEM and aerial photographs of the peatlands in the Hodder catchment, Lancaster, UK, which were assumed to be representative of the peatlands across the UK. The overland flow roughness is parameterised based on field observations made by Holden et al. (2008), where flow roughness was observed to vary both with plant cover and flow depth; this study is the only known investigation that quantifies overland flow roughness on peatlands. This parameterisation is represented by the parameter $b$, which is a proxy for the Darcy Weisbach roughness coefficient (see Ballard et al., 2011, for the full derivation). Hydraulic conductivity ranges were estimated based on information from Letts et al. (2000) and Holden and Burt (2003). The acrotelm and catotelm porosities $\left(\varepsilon_{\mathrm{a}}\right.$ and $\left.\varepsilon_{\mathrm{c}}\right)$ are set as functions of their respective hydraulic conductivities following the relationship presented by Letts et al. (2000) plus a random term between \pm 0.05 to account for natural variability and uncertainty in this relationship. The drain depth is fixed at $0.6 \mathrm{~m}$ and the drains were blocked at $12.5 \mathrm{~m}$ intervals (typical average dam spacing, Armstrong et al., 2009).

100 parameter sets were sampled from the prescribed ranges where each set can be considered to represent a possible peatland site. This does not account for any natural correlation of model parameters, for example, a site might be likely to have a high hydraulic conductivity in the catotelm and acrotelm simultaneously, and this limitation must be considered when interpreting results. The same 100 parameter sets were used for each of the possible peatland land 
Table 2. Parameter ranges for scenario Monte Carlo simulations.

\begin{tabular}{llcc}
\hline & & \multicolumn{2}{c}{ Ranges for Monte Carlo Simulations } \\
\cline { 3 - 4 } Parameter & & Lower value & Upper value \\
\hline Acrotelm hydraulic conductivity $\left(\mathrm{m} \mathrm{d}^{-1}\right)$ & $K_{\text {sa }}$ & 0.05 & 1 \\
Catotelm hydraulic conductivity $\left(\mathrm{m} \mathrm{d}^{-1}\right)$ & $K_{\mathrm{Sc}}$ & 0.001 & 0.05 \\
Thickness of acrotelm (m) & $d_{\mathrm{a}}$ & 0.075 & 0.2 \\
Drain angle (degrees) & $\alpha$ & 5 & 25 \\
Surface slope (degrees) & $\beta$ & 2 & 12 \\
Plant cover (overland flow roughness) & $b$ & Sphagnum \& Juncus (roughest, 1.91) & Eriophorum (smoothest,5.05) \\
Manning's $n$ (drain roughness) & $n$ & 0.05 & 0.6 \\
Drain spacing (m) & $W$ & 10 & 25 \\
\hline
\end{tabular}
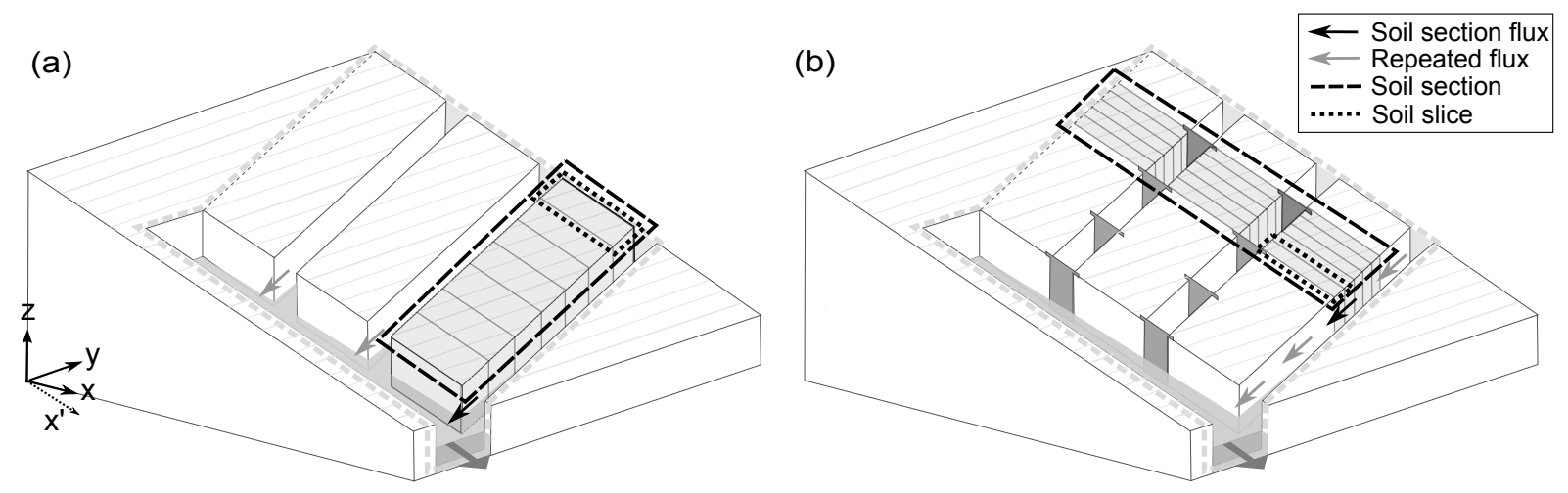

Fig. 2. Schematic of numerical representation of drained (a) and blocked drain (b) hillslope, demonstrating the concepts of soil sections and soil slices and the location of repeated fluxes.

management scenarios, with the different drainage management scenarios represented only by differences in model structure.

This approach also assumes that there is no change in the physical properties of the peatland following changes in the drainage regime. However, as evidence in the literature suggests drainage management can be associated with physical changes in the peatlands, we also investigate the potential importance of these changes by testing the sensitivity of simulated flow peaks to expected non-stationarity in parameters. Five of the model parameters are assumed to potentially change: drain roughness, surface roughness, acrotelm thickness, and acrotelm and catotelm hydraulic conductivities (and therefore implicitly the acrotelm and catotelm porosities, the transmissivity and total soil storage). Table 1 indicates the assumed direction of change for each of the parameters that may occur following drainage management change. This data is based on the literature cited in the introduction, and the assumed reversal of these changes following drain blocking.

Drainage management scenarios (intact, drained, blocked drains) were applied to each sampled site, and the change in flow response assessed using the simulation model. The flow responses were simulated for a $1 \mathrm{yr}$ period with outputs every $15 \mathrm{~min}$. A five day warm up period was used to ensure that the responses were independent of the initial conditions. Rainfall data and evapotranspiration data are taken from a blanket peatland site in the Hodder catchment, UK, for the period 1 December 2008 to 31 November 2009. Rainfall data was from a rain gauge located at SD 6342455801 at a 5 min resolution. This data was summed to create a $15 \mathrm{~min}$ resolution input for the model. Potential evapotranspiration was determined using the Penman-Monteith equation (Allen et al., 1998) assuming a reference crop and inputs of $15 \mathrm{~min}$ resolution AWS data from a station located at SD 6313154971.

An events-based analysis has been used to investigate the impacts of drainage management change on peak flows. The time series were broken down into discrete events using a method similar to that of Pearce and Rowe (1981). Rainfall events were identified as periods of rainfall followed by a minimum period without rainfall (in order to achieve independence of events). A rain event was defined for a period of rain lasting less than $4 \mathrm{~h}$ followed by a $1 \mathrm{~h}$ dry period, or a longer period of rain followed by a $2 \mathrm{~h}$ dry period. As we are particularly interested in high rainfall events, we have discarded events where less than $5 \mathrm{~mm}$ of rain was recorded. This led to a total of 80 events in the $1 \mathrm{yr}$ period. 


\section{Sensitivity analysis - results}

This section presents the results from the model simulations. The analysis focuses on the peak flow responses and the differences in these responses between drainage management scenarios for each of the 100 hypothetical peatland sites. The analysis starts with a general examination of the magnitude and variability in peak flow change for a large sample of rainfall events. We then use regression to identify which peatland properties govern peak flow magnitudes for the largest events and the differences in peak flow magnitudes following drainage management change. Finally, the significance of hydrological non-stationarity associated with drainage management is assessed.

\subsection{Impact of drainage management - influence of event size}

For each of the 80 rainfall events, and for each of the 100 hypothetical peatland sites, the peak flow for the intact, drained and drain blocked scenarios $\left(q_{\mathrm{i}}, q_{\mathrm{d}}\right.$ and $\left.q_{\mathrm{b}}\right)$ was extracted, and the peak flow changes $\Delta q_{\mathrm{di}}=q_{\mathrm{d}}-q_{\mathrm{i}}$, $\Delta q_{\mathrm{db}}=q_{\mathrm{d}}-q_{\mathrm{b}}, \Delta q_{\mathrm{ib}}=q_{\mathrm{i}}-q_{\mathrm{b}}$ were calculated. For each of these three changes, the 8000 samples of $\Delta q$ were considered together, in order to assess the general impacts across a range of event magnitudes. Results are shown in Fig. 3. To develop this figure, the 8000 samples were ordered from the smallest to largest events, based on the magnitude of the peak flow as shown on the x-axis of Fig. 3. The sorted runoff was then split into 80 groups (each containing 100 events), for which the mean, 5th, 25th, 75th and 95th percentiles of $\Delta q$ were calculated. Note that the 80 groups do not necessarily contain events from all of the hypothetical peatland sites; nevertheless, the general trends are clear.

Figure 3 indicates that the differences in runoff between drainage management types vary with the magnitude of the runoff peak. Drainage is observed to be effective in reducing flow peaks for some lower flow events (left hand side of Fig. 3a), but for most events consistently increases peak flows. Only for the very largest flows from drained peatlands are consistent decreases in peak flows observed following drain blocking (Fig. 3b). Figure 3c highlights the difference between intact and drain blocked peatlands, indicating that drain blocking does not recreate the hydrological response of intact peatlands: blocked drains consistently produce higher peak flows than intact peatland. The reason for this is discussed later. The maximum peak flow for the intact peatland is significantly smaller for that of the drained site, hence the difference in $\mathrm{x}$-axis scales between Fig. 3a, b and c.

\subsection{Peatland properties controlling peak flows}

The wide uncertainty bounds in Fig. 3 demonstrate the importance of considering the properties of the peatland when predicting impacts of drainage management. A sensitivity analysis developed some insight into the important peatland properties. For each of the hypothetical peatland sites, the rainfall events that led to the 10 largest peak runoff events $(\boldsymbol{r})$ were identified (including only the largest peaks in the sample is considered suitable in the context of flooding), then the mean of the peak flows produced by these 10 events was calculated $(\bar{q}(\boldsymbol{r}))$. The sensitivity of $\bar{q}(\boldsymbol{r})$ to each of the model parameters can be quantified by conducting a regression analysis with the peatland properties (i.e. the model parameters) as the regressors (Saltelli et al., 2004).

The model parameter values were standardised to lie in the range -0.5 to 0.5 (i.e. for a given parameter vector $\boldsymbol{\theta}$, $\theta_{\text {std }}=\left(\boldsymbol{\theta}-\theta_{\min }\right) /\left(\theta_{\max }-\theta_{\min }\right)-0.5$, where $\theta_{\max }$ and $\theta_{\min }$ are given in Table 2) to ensure that all parameters have equal variance and a zero mean (within the sampling error). Standardising the regressors allows the regression coefficients to act as relative measures of the parameter sensitivity (Saltelli et al., 2004). Three extra regressors were based on combinations of the model parameters to represent additional physically relevant properties. These were the transmissivity ( $T$, the hydraulic conductivity integrated over the depth), the drain slope ( $\beta_{\mathrm{d}}$, based on the site slope and drain angle), and the total soil storage ( $S$, the porosity integrated over the depth). A stepwise multiple linear regression was performed for each of the drainage management scenarios to predict $\bar{q}(\boldsymbol{r})$, where parameters with $\mathrm{p}$-values less than 0.05 were added, and parameters with p-values greater than 0.1 were removed. Table 3 shows the significant parameters $(\boldsymbol{\theta})$ and their regression coefficients (in increasing order of significance) as well as the $\mathrm{R}^{2}$-values corresponding to the progressive addition of parameters.

The results from these regressions provide further understanding about the dominant flow mechanisms in each of the drainage management scenarios. The peak flow response from the intact sites is dominated by the parameters governing overland flow. As intact peatlands tend to have higher water tables (Holden et al., 2004), there is generally very little subsurface storage to accommodate large influxes of rainfall. The excess rainfall runs off the surface, and the magnitude of the peaks is related to the travel time along overland flow paths, which is governed by both the slope and the overland flow roughness. For the drained scenarios, parameters related to the speed of delivery in the drains are important. In contrast to the intact sites, the response from drained sites also has some dependency on subsurface properties. Drawdown caused by drains is observed to be quite localised, therefore a combination of closer spaced drains and higher transmissivity will lead to a greater increase in subsurface storage between rainfall events, and therefore an increased capability to accommodate incoming rainfall and lower flow peaks. For the blocked scenarios, the dominant peak flow path shifts back to being along the peatland surface, which is indicated by the sensitivity to both the site slope and flow roughness. However, a strong dependence on the transmissivity remains, for the same reasons as for the drained scenarios. 

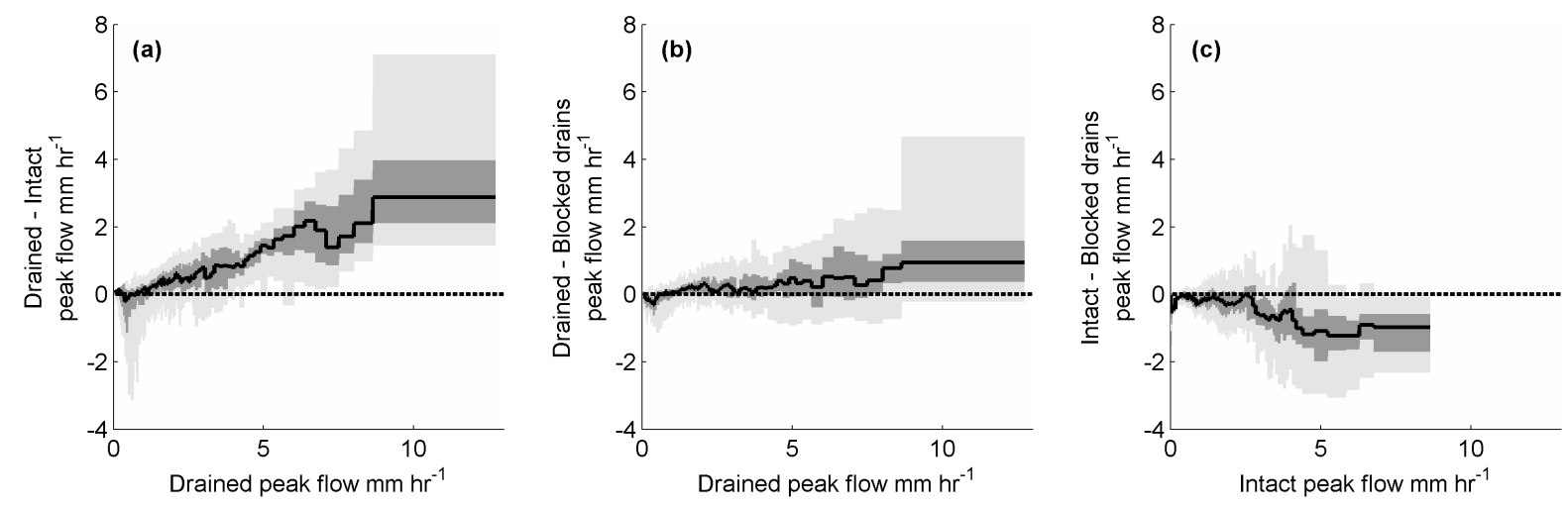

Fig. 3. Difference in peak flows: (a) drained minus intact (positive values indicate increases in peak flows following drainage); (b) drained minus blocked (positive values indicate decreases in peak flows following drain blocking); (c) intact minus blocked (positive values indicate that blocked sites have lower peak flows than intact sites). Light grey areas are the 5-95\% range, dark grey areas are the 25-75\% range, and the heavy black line is the median difference.

Table 3. Regression models for intact, drained and blocked values of $\bar{q}(\boldsymbol{r})$. The parameters and their regression coefficients are shown in increasing order of significance. $\mathrm{R}^{2}$-values are cumulative, demonstrating the effect of progressive addition of parameters.

\begin{tabular}{|c|c|c|c|c|c|c|c|c|}
\hline \multicolumn{3}{|c|}{ Intact } & \multicolumn{3}{|c|}{ Drained } & \multicolumn{3}{|c|}{ Blocked } \\
\hline$\theta$ & Coeff. & $R^{2}$ & $\theta$ & Coeff. & $R^{2}$ & $\theta$ & Coeff. & $R^{2}$ \\
\hline$\beta$ & 1.69 & 0.46 & $n$ & -2.52 & 0.52 & $b$ & 1.90 & 0.52 \\
\hline$b$ & 1.56 & 0.83 & $T$ & -1.46 & 0.60 & $T$ & -1.48 & 0.66 \\
\hline \multirow[t]{5}{*}{$n$} & 0.69 & 0.91 & $\beta_{\mathrm{d}}$ & 1.05 & 0.72 & $\beta$ & 1.19 & 0.82 \\
\hline & & & $W$ & 0.95 & 0.86 & $W$ & 0.41 & 0.86 \\
\hline & & & $b$ & 0.67 & 0.90 & $K_{\mathrm{c}}$ & 0.22 & 0.87 \\
\hline & & & $\beta$ & 0.58 & 0.91 & & & \\
\hline & & & $\varepsilon_{\mathrm{c}}$ & -0.48 & 0.92 & & & \\
\hline Intercept & 4.44 & & Intercept & 6.56 & & Intercept & 6.12 & \\
\hline
\end{tabular}

\subsection{Impacts of peatland drainage management - sensitivity to peatland properties}

The type of peatlands most amenable to drainage management, in terms of potential for reducing downstream flood peaks, can also be explored using regression. The average change in event peak flows (for the ten largest events) associated with drainage management $(\Delta \bar{q}(\boldsymbol{r}))$ is defined as

$\Delta \overline{q_{\mathrm{d}-\mathrm{i}}}(\boldsymbol{r})=\frac{\overline{q_{\mathrm{d}}}(\boldsymbol{r})-\overline{q_{\mathrm{i}}}(\boldsymbol{r})}{\overline{q_{\mathrm{d}}}(\boldsymbol{r})} \times 100$

$\Delta \overline{q_{\mathrm{d}-\mathrm{b}}}(\boldsymbol{r})=\frac{\overline{q_{\mathrm{d}}}(\boldsymbol{r})-\overline{q_{\mathrm{b}}}(\boldsymbol{r})}{\overline{q_{\mathrm{d}}}(\boldsymbol{r})} \times 100$

where subscripts "i", "d", and "b" indicate values for intact, drained and blocked drain simulations.

Values of $\Delta \overline{q_{\mathrm{d}-\mathrm{i}}}(\boldsymbol{r})$ and $\Delta \overline{q_{\mathrm{d}-\mathrm{b}}}(\boldsymbol{r})$ were calculated for each of the 100 hypothetical peatland sites. $\Delta \overline{q_{\mathrm{d}-\mathrm{i}}}(\boldsymbol{r})$ had 5th and 95th percentile values of $6.3 \%$ and $40.6 \%$, respectively, and a median change of $26.6 \%$ (positive indicates an increase in peak flows following drainage). For 98 of the hypothetical peatland sites, $\Delta \overline{q_{\mathrm{d}-\mathrm{i}}}(\boldsymbol{r})$ was greater than zero and for 83 of these sites, all 10 events showed an increase in flow peaks. For drain blocking, $\Delta \overline{q_{\mathrm{d}-\mathrm{b}}}(\boldsymbol{r})$ had 5th and 95th percentile values of $-18.7 \%$ and $25.3 \%$, respectively, and a median change of $4 \%$ (where positive values indicate a reduction in peak flow following drain blocking). $\Delta \overline{q_{\mathrm{d}-\mathrm{b}}}(\boldsymbol{r})$ for 67 of the sites was greater than zero (i.e. blocking had reduced flood peaks) and for 44 of these, all 10 events showed a reduction in flood peaks. Of the remaining 33 sites, none showed a consistent increase in flood peaks following drain blocking.

A regression was conducted in order to predict $\Delta \bar{q}(\boldsymbol{r})$ using the model parameters (and $T, \beta_{\mathrm{d}}$ and $S$ ) as regressors. The $\mathrm{R}^{2}$-values corresponding to the progressive addition of parameters into the regression are shown in Table 4. The parameters and their regression coefficients are shown in increasing order of significance, as determined through the stepwise regression. Comparing Tables 3 and 4, note that some parameters that significantly affect flood peak magnitude for individual drainage scenarios do not significantly 
Table 4. Regression models to predict $\Delta \overline{q_{\mathrm{d}-\mathrm{i}}}(\boldsymbol{r})$ and $\Delta \overline{q_{\mathrm{d}-\mathrm{b}}}(\boldsymbol{r})$. The parameters and their regression coefficients are shown in increasing order of significance. $\mathrm{R}^{2}$-values are cumulative, demonstrating the effect of progressive addition of parameters.

\begin{tabular}{|c|c|c|c|c|c|}
\hline \multicolumn{3}{|c|}{ Drained minus intact } & \multicolumn{3}{|c|}{ Drained minus blocked drains } \\
\hline$\theta$ & Coeff. & $R^{2}$ & $\theta$ & Coeff. & $R^{2}$ \\
\hline$n$ & -14.87 & 0.21 & $n$ & -31.13 & 0.66 \\
\hline$T$ & -13.16 & 0.30 & $b$ & -13.57 & 0.76 \\
\hline$\beta$ & -12.28 & 0.49 & $W$ & 8.60 & 0.86 \\
\hline$b$ & -12.25 & 0.62 & $\alpha$ & 5.48 & 0.88 \\
\hline$W$ & 8.43 & 0.79 & $T$ & -3.44 & 0.89 \\
\hline$K_{\mathrm{c}}$ & -4.83 & 0.82 & & & \\
\hline$\alpha$ & 4.16 & 0.84 & & & \\
\hline Intercept & 26.6 & & Intercept & 4.00 & \\
\hline
\end{tabular}

affect the impact of a change in drainage management. Figure 4 shows the goodness of fit for the regressions.

The regression shows that the greatest increase in peak flows following drainage of peatlands occurs when the new drains are smooth, at a steeper angle and with larger spacing and when the peat itself has low transmissivity, hydraulically rougher plant species and a low site slope. The roughness and the angle of the drain both lead to quick drain flows. Lower transmissivity and higher drain spacing cause the peat drainage to be very ineffective, and a low slope and rough plant cover indicates that peak flows from the site prior to drainage were already well attenuated.

The regression also indicates that the best drains to block, in terms of greatest reduction in the largest peak flows, are at sites with larger drain spacing, steeper drain angle, rougher plant cover, smoother drains and lower transmissivity. At larger drain spacing, any additional soil storage capacity produced by the drains is minimised, due to the localised effects of drawdown in low hydraulic conductivity peatlands. A steeper drain angle combines with the site slope to give a steeper drain slope. Along with low hydraulic roughness of the drain, this leads to faster conveyance of water in the drain network. If the peatland surface has high hydraulic roughness, the speed of the new flow paths from the blocked drains down the peatland surface can be slower than those in the drains.

\subsection{Impacts of peatland drainage management - sensitivity to non-stationarity of peatland properties}

The analysis to this point has assumed that the drain, soil and vegetation properties do not change with drainage management. This is addressed here by simulating the effects of parameter non-stationarity. The analysis considers only the potential non-stationarity of the model parameters and does not consider the potential non-stationarity of site geometry (i.e. erosion and deposition within channels) or of the model structures. We assume that peak flow response to parameter
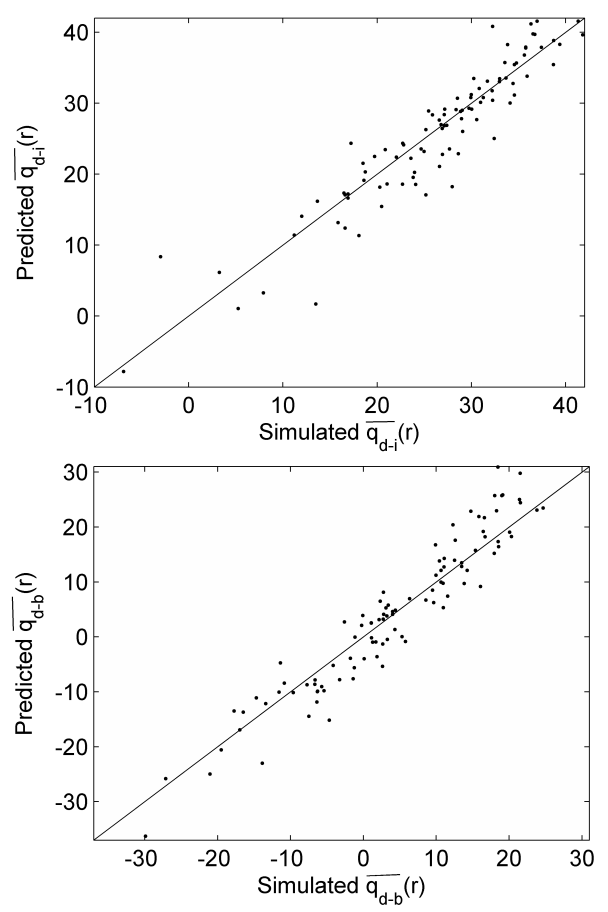

Fig. 4. Regression estimates of $\Delta \bar{q}(\boldsymbol{r})$ versus the corresponding simulated values.

perturbations can be adequately represented with the linear regression model. The high $\mathrm{R}^{2}$-values achieved using the regressions indicate that the linear approximation is useful at least within the sampled range of flows. Using the regression models rather than the physics based models allows us to examine effects of a wider sample of parameter perturbations, due to its significantly lower computational time.

The regression models specified in Table 4 are based on the assumption that the same parameter set applies before and after the drainage management change. However, because the regression models specified in Table 3 simulate the before and after responses independently, they can be used to introduce non-stationarity into the parameter values, without the necessity of additional physics based model simulations. The change in peak flow, $\Delta \bar{q}(\boldsymbol{r})$, can be indirectly calculated using the mean peak flows predicted for each land management scenario from the regression in Table 3 (denoted from here on as $\overline{\hat{q}}(\boldsymbol{r})$ ) in Eqs. (1) and (2) (instead of using the direct model outputs). This introduces a small error in the calculation of $\Delta \bar{q}(\boldsymbol{r})$ relative to the direct regression presented in Table 4 , increasing the root mean square errors from $3.7 \%$ to $3.9 \%$ and $4.0 \%$ to $4.3 \%$ for the drained-intact and drained-blocked scenarios, respectively.

We have arbitrarily assumed that the maximum changes in any of the site properties listed in Table 1 would be $10 \%$ of the pre-change parameter values. To examine the potential impacts of multiple changes in properties following land use change, 1000 random perturbation sets were sampled $(\Delta \boldsymbol{\theta})$. 
Each set contains a value between -0.1 and 0.1 for each of the parameters shown in Table 1, where negative changes are sampled from -0.1 to 0 , positive changes from 0 to 0.1 and changes in both directions from -0.1 to 0.1 . For each of the 100 hypothetical sites 1000 perturbed parameter sets were derived $(\boldsymbol{\theta}+\Delta \boldsymbol{\theta})$. The change in $\Delta \bar{q}(\boldsymbol{r})$ related to nonstationarity in physical properties, $d(\Delta \bar{q}(\boldsymbol{r}))$, is calculated as

$$
\begin{aligned}
& d\left(\Delta \overline{q_{\mathrm{d}-\mathrm{i}}}(\boldsymbol{r})\right)= \\
& \left(\frac{\overline{\hat{q}_{\mathrm{d}}}(\boldsymbol{\theta}, \boldsymbol{r})-\overline{\hat{q}_{\mathrm{i}}}(\boldsymbol{\theta}, \boldsymbol{r})}{\overline{\hat{q}_{\mathrm{d}}}(\boldsymbol{\theta}, \boldsymbol{r})}-\frac{\overline{\hat{q}_{\mathrm{d}}}(\boldsymbol{\theta}+\Delta \boldsymbol{\theta}, \boldsymbol{r})-\overline{\hat{q}_{\mathrm{i}}}(\boldsymbol{\theta}, \boldsymbol{r})}{\overline{\hat{q}}_{\mathrm{d}}(\boldsymbol{\theta}+\Delta \boldsymbol{\theta}, \boldsymbol{r})}\right) \times 100 \\
& d\left(\Delta \overline{\mathrm{q}_{\mathrm{d}-\mathrm{b}}}(\boldsymbol{r})\right)= \\
& \left(\frac{\overline{\hat{q}_{\mathrm{d}}}(\boldsymbol{\theta}, \boldsymbol{r})-\overline{\hat{q}_{\mathrm{b}}}(\boldsymbol{\theta}, \boldsymbol{r})}{\overline{\hat{q}_{\mathrm{d}}}(\boldsymbol{\theta}, \boldsymbol{r})}-\frac{\overline{\hat{q}_{\mathrm{d}}}(\boldsymbol{\theta}, \boldsymbol{r})-\overline{\hat{q}_{\mathrm{b}}}(\boldsymbol{\theta}+\Delta \boldsymbol{\theta}, \boldsymbol{r})}{\hat{\hat{q}}_{\mathrm{d}}(\boldsymbol{\theta}, \boldsymbol{r})}\right) \times 100
\end{aligned}
$$

where the first part of the equation is the equivalent of Eqs. (1) and (2) and the second part is the predicted change in mean peak flow including parameter perturbations. The variation in $d(\Delta \bar{q}(\boldsymbol{r}))$, plotted across the range of $\Delta \bar{q}(\boldsymbol{r})$, is shown in Fig. 5.

The median value of $d(\Delta \bar{q}(\boldsymbol{r}))$ for the drained minus intact scenario is approximately zero, indicating that the general effect of non-stationarity is unpredictable in this case. This is largely related to the uncertainty in the direction of change of the channel roughness with time, which is a particularly important control on the impact of drainage, as explained previously. For drain blocking, the median value of $d(\Delta \bar{q}(\boldsymbol{r}))$ is consistently below zero, indicating that peak flows following drain blocking are generally overestimated when assuming parameter stationarity and that reductions in peak flows greater than those predicted by the regression in Table 4 could be expected. This effect decreases with increasing $\Delta \bar{q}(\boldsymbol{r})$.

\section{Discussion}

A new hydrological model has been developed to represent the hydrological response following the blocking of open ditches in upland blanket peatlands. A series of virtual experiments has been performed using this model in order to investigate the potential changes in hydrological regime, and in particular peak flows, following management interventions. Sensitivity analysis has been conducted in order to investigate the sensitivity of both the responses and the impacts of drainage management to the peatland properties (as represented by the model parameters), as well as to identify those processes that are contributing most to modelled differences in flows.

These virtual experiments indicate that peatland drainage almost consistently increases flow peaks, although the magnitude of the change is variable dependent on properties of both the drainage network and the peat itself. This is consistent with observations of the impacts of peatland drainage
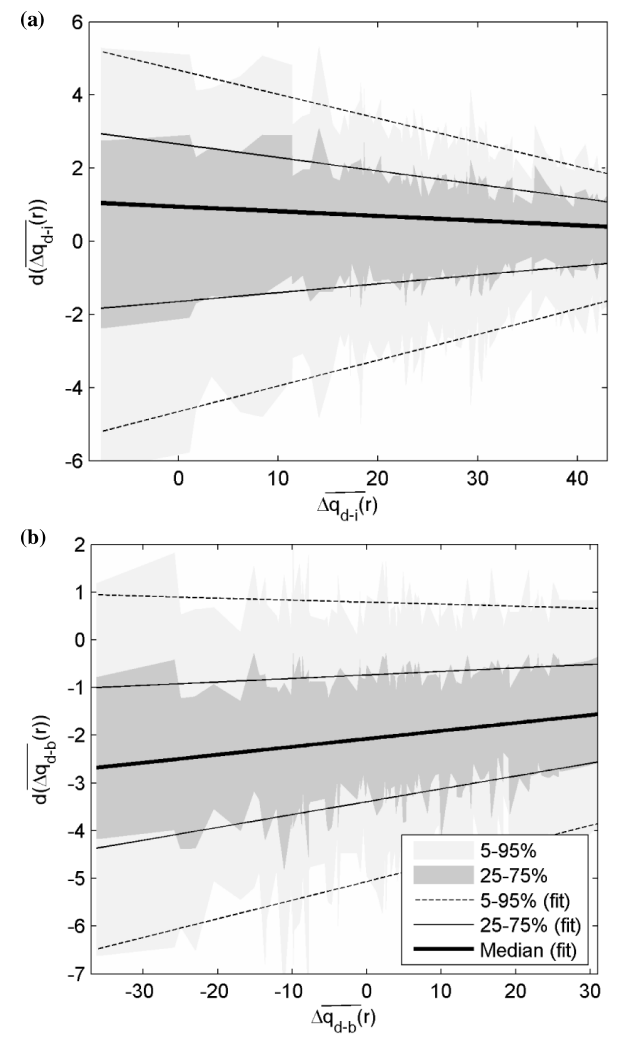

Fig. 5. $\Delta \bar{q}(\boldsymbol{r})$ versus $d(\Delta \bar{q}(\boldsymbol{r}))$ following parameter perturbation for (a) drained minus intact (b) drained minus blocked. Light grey areas: 5-95\% range; dark grey areas: $25-75 \%$ range. The heavy black line is the best fit of the median, the dashed black lines are the best fit of the 25-75\% range and the light grey lines are the best fit for the 5-95\% range.

on peak flows reported in the literature (Ahti, 1980; Conway and Millar, 1960; Holden et al., 2006; Robinson, 1986; Stewart and Lance, 1991). The low hydraulic conductivities of peatlands mean that drawdown caused by drainage is small (Robinson, 1986; Stewart and Lance, 1983), and takes a long period to develop; therefore, drainage of peatlands is only observed to be efficient for attenuating very small peak flows that occur after periods without rain.

Our virtual experiments also show that peatland drain blocking does not always reduce flow peaks. Owing to the low rates of evaporation and high rates of rainfall typical of peatland areas, the storage created by the blocked drains is significant only for small events, and/or after long periods without rain. In these cases, the peak flows can be dramatically decreased following drain blocking. The largest events, as defined by simulated peak flow under drained conditions in Fig. 3b, indicate that drain blocking consistently reduces peak flows, however interpretation of Fig. $3 \mathrm{~b}$ is not as straightforward as this: drained sites that were less flashy produced relatively lower peak flows even for the large rainfall events, and hence are included in the samples towards the 
left of Fig. 3b. In many of these cases, implementing drain blocking scenarios led to increases in peak flows. This is because the relative speed that water can exit the model domain via the overland and drain flow paths governs the difference in response. When the drains are blocked flow paths switch as shown in Fig. 1 and are directed overland; hence, the more critical pathway is the overland flow path. Overland flow velocities are dependent on the depth-dependent surface roughness, the depth and slope of the site. Even if overland flow roughnesses are greater than those in the drains, the velocities of the overland flow compared with those in the ditches can be greater if the drain angle is low such that the drain slope is significantly shallower than the downslope flow path. As steeper slopes increase flow velocities, both in the drains and for the overland flow, in the regression analysis shown in Table 4, the slope was not found to be a significant parameter. The angle, however, was significant, as this governs the relative difference in slopes between the drains and the overland flow paths.

Comparison between the intact and drain blocked peatland scenarios indicates that peatland drain blocking does not lead to conditions equivalent to intact peatlands. This is due to the way that the overflowing blocked ditches focus the water spilling onto the downslope peatland. Deeper water tends to move faster (Manning's equation), and furthermore the hydraulic roughness of peatlands is observed to decrease with increasing depth (Holden et al., 2008); therefore, this concentrated stream can flow more rapidly than natural flows across the surface of an intact peatland. This effect also compounds as the flows cascade downslope.

The parameter sampling initially used in the virtual experiments did not take into account the change in the parameter values with time, and therefore could be considered to be indicative of the systems immediately following drainage management change. To explore longer term effects, a perturbation analysis was used to investigate the impact of nonstationary drain, soil and vegetation conditions. The factor most affecting the long-term impact of installing drainage is the drain roughness value. If the drains revegetate, the regression equation in Table 4 will tend to overestimate the increase in peak flows following drainage, and if the drains erode and become smoother with time, the equation will underestimate the increase in peak flows. The variation in $\Delta \bar{q}(\boldsymbol{r})$ following drain blocking is mostly sensitive to changes in peatland vegetation, where colonisation by hydraulically rougher species leads to a greater reduction in peak flows. This highlights the importance of actively undertaking activities to support the recolonisation of species such as Sphagnum in conjunction with drain blocking.

The results presented in this analysis are based on parameters that were selected independently of each other from the prior ranges given in Table 2. However, in reality, correlation of some of the parameter values would be expected. Observations have shown that natural re-vegetation tends to occur in drains with shallow slopes (Holden et al., 2007), and that erosion is more common on more steeply sloped drains, thereby suggesting correlation between drain slope and drain roughness. At low drain spacings and higher hydraulic conductivities, the effect of water table drawdown is more significant, therefore reducing the total cover of the most hydraulically rough plant species (i.e. sphagnum) (Coulson et al., 1990). There is also likely to be a relationship between the peatland surface roughness and the drain roughness; it seems unlikely that the drains would be highly vegetated if the surface is not; however, there seems to be no published evidence to support this speculation.

Structural simplifications in the hydrological models were employed with the rationale that more complex representations could not be justified given the data scarcity. This implies that model improvements could be made if sufficient supporting data were available. The results from the simulations conducted in this study suggest that surface flow paths are the dominant control on peak flow response. Investigations into peatland surface roughness and drain roughness (for example, through sprinkler experiments) that could assist in refining the parameter ranges would lead to significant reductions in the model prediction uncertainty. Such studies may also assist with the conceptualisation of the surface runoff processes. In particular, the field investigations could build on the study of Holden et al. (2008), to include a wider range of peatland plant species, as well as estimates for mixed species sites and to explore the impacts of microtopography. Particular emphasis should also be placed on the drain roughness, for which the Holden et al. (2008) study only collected a limited data set.

There remains some uncertainty in the conceptualisation of blocked drains. The configuration is a representation of an ideal drain blocking system, but alternative methods are also employed where overflow from the reservoir created by the drain block spills not downslope, but into the downstream dam (or some combination of the two) (Armstrong et al., 2009). In many cases, the drains are blocked using peat excavated from the side of the drains; the excavated peat is used to block the drains immediately downstream of the excavation. This leads to increased storage of the newly created reservoir (and will also affect the spilling process), which is not accounted for in the present model. The sensitivity of the reservoir spilling process to variability in the elevation of the top of the drain is not well understood. High variability in the elevation of the top of the drain may lead to more diffuse spilling on to the downslope peat, and hence reduced flow velocities. Given the significance of the differential flow velocities between the peatland surface and drains in controlling the ultimate impact of drain blocking, observations from blocked drain sites could assist in reducing the conceptual uncertainty in these predictions.

Although arbitrary, the averaging of peak flows for the ten largest events works to remove some of the response dependence on the nature of the rainfall event and initial conditions, which have been found to influence the relative 
sensitivities of the model parameters (Ballard, 2011). To some extent, the results are sensitive to the number of rainfall events included in $(\boldsymbol{r})$ (assuming they are still sampled from the larger of the 80 rainfall events). However, the order of parameter sensitivity (at least for the most sensitive parameters) generally remains the same, as does the sign of the regression coefficients. Therefore, the method is useful insomuch as it provides a general measure of the magnitude and direction of change in peak flows and the importance ranking of the parameters. However, although averaging over many events is a very useful technique for sensitivity analysis (particularly in order to identify those processes and properties that are controlling changes in runoff response), in terms of predicting impacts of change, the approach neither accounts for the variability between events nor for the non-linearities involved. For making predictions, the simulation model would need to be run.

The principal limitations of the numerical experiments reported in this paper are (1) the results are, by design, generalisations, with considerable variability over the range of sites considered, and any site-specific analysis would need to be supported by sufficient data to estimate suitable model parameter values. In particular, there is high uncertainty in the hydraulic roughnesses of both drains and land surface, which are critical parameters when predicting impacts. (2) The model structure has been tested only on a drained peatland site (Ballard et al., 2011). If such data were available, the model should be tested against field observations from a range of sites including some which are intact and some with blocked drains. (3) The assumption of linearity used in the regression models to investigate parameter sensitivities appeared to be suitable in this instance. However, should the parameter ranges be changed (either widened or tightened) the sensitivities are likely to change as well. Therefore, the sensitivities should be viewed as indicative rather than strictly quantitative. (4) The results from this study only reflect changes at the $200 \mathrm{~m} \times 200 \mathrm{~m}$ scale. At the catchment scale, particularly when only parts of the catchment have changes in land use, the impacts will also be dependent on the stream routing and connectivity (e.g. Lane et al., 2004). (5) The range of analysed rainfall events did not include any extreme flood events, with the maximum flood peak having an estimated return period of only $1.4 \mathrm{yr}$. Further research should include more extreme events, with the hypothesis that drainage management has less impact for larger events (as has been modelled for other land use change impacts; e.g. Wheater et al., 2008). (6) There is scope for extending the range of peatland management questions. For example the model could also be used to investigate a range of drain block spacings, in order to provide some guidance to practitioners. (7) The inferences about causal mechanisms may be dependent on the chosen model structures employed within this study.

\section{Conclusions}

This study has used a simplified physics-based model that encompasses our understanding of important peatland drainage processes to produce evidence about and uncertainty analysis of the effects of drainage management on flood peaks. The model suggests that drainage of peatlands will increase peak flows and that drain blocking will usually decrease peak flows but may actually increase them in some cases. The results provide indications of areas that are most likely to benefit, in terms of flood generation, from drain blocking. The model predicts that drains that are steeper and smoother are most likely to show the greatest reduction in peak flows following drain blocking. Drains in this state are also most likely to benefit from drain blocking in terms of reducing sediment transport and erosion. The analysis also suggests that if drains are already highly vegetated, it is possible that blocking them could actually increase peak flows. As there is especially little field-evidence about the hydrological nonstationarity associated with changes in peatland drainage management, a perturbation analysis was performed using the model. The analysis suggests that greater reductions in peak flows following drain blocking may be observed with time as hydraulically rougher peatland species begin to recolonise, although the magnitude of these changes will depend on the degree of recolonisation and the state of the vegetation prior to drain blocking. Overall, however, the variability of results obtained emphasises the importance of new field studies to constrain model uncertainty and allow sitespecific conclusions to be drawn. In particular investigations of surface and drain runoff response would most greatly reduce prediction uncertainty and also potentially improve the model process representation.

Acknowledgements. This research was funded by the UK Flood Risk Management Research Consortium Phase 2, EPSRC Grant EP/F020511/1. The rainfall and AWS data used in this study were collected by Josie Geris under EA project SC060092. Thank you to Jim Freer and an anonymous reviewer for the comments received through HESS, and to Keith Beven and Adrian Butler who reviewed this paper as part of a $\mathrm{PhD}$ exam and provided a number of useful improvements.

Edited by: J. Freer

\section{References}

Ahti, E.: Ditch spacing experiments in estimating the effects of peatland drainage on summer runoff, Proceedings of the International Symposium on Influence of Man on Hydrological Regime, Helsinki, IAHS-AISH P., 130, 49-53, 1980.

Allaby, M. (Ed): Oxford Dictionary of Earth Sciences, Oxford University Press, Oxford, 2008.

Allen, R. G., Pereira, L. S., Raes, D., and Smith, M.: Crop evapotranspiration-Guidelines for computing crop water 
requirements-FAO Irrigation and drainage paper 56, FAO, Rome, 300 pp., 1998.

Armstrong, A., Holden, J., Kay, P., Foulger, M., Gledhill, S., Mcdonald, A. T., and Walker, A.: Drain-blocking techniques on blanket peat: A framework for best practice, J. Environ. Manage., 90, 3512-3519, 2009.

Armstrong, A., Kay, B., McDonald, A. T., Gledhill, S., Foulger, M., and Walker, A.: The impact of peatland drain-blocking on dissolved organic carbon loss and discoloration of water; results from a national survey, J. Hydrol., 381, 112-120, 2010.

Ballard, C.: The role of physics based models for simulating runoff responses to rural land management scenarios, $\mathrm{PhD}$ thesis, Imperial College London, 324 pp., 2011.

Ballard, C., McIntyre, N., Wheater, H. S., Holden, J., and Wallage, Z. E.: Hydrological modelling of drained blanket peat, J. Hydrol., 407, 81-93, 2011.

Bonn, A., Allott, T. E. H., Hubacek, K., and Stewart, J.: Introduction: drivers of change in upland environments: concepts, threats and opportunities, in: Drivers of change in upland environments, edited by: Bonn, A., Allott, T. E. H., Hubacek, K., and Stewart, J., Routledge, Oxon, 1-10, 2009.

Conway, V. M. and Millar, A.: The hydrology of some small peatcovered catchments in the northern Pennines, J. Inst. Water Engin., 14, 415-424, 1960.

Coulson, J. C., Butterfield, J. E. L., and Henderson, E.: The Effect of Open Drainage Ditches on the Plant and Invertebrate Communities of Moorland and on the Decomposition of Peat, J. Appl. Ecol., 27, 549-561, 1990.

Evans, M. G., Burt, T. P., Holden, J., and Adamson, J. K.: Runoff generation and water table fluctuations in blanket peat: evidence from UK data spanning the dry summer of 1995, J. Hydrol., 221, 141-160, 1999.

Ewen, J., O’Donnell, G., Mayes, W. M., Geris, J., and O'Connell, E.: Multiscale Experimentation, Monitoring and Analysis of Long-term Land Use Change and Flood Risk (EA Project SC060092): Final Science Report, Newcastle University, 133 pp., 2010.

Geris, J. R. M. C.: Multiscale impacts of land use/management changes on flood response in the river Hodder catchment, NorthWest England, PhD Thesis, Newcastle University, 2012.

Holden, J. and Burt, T. P.: Hydraulic conductivity in upland blanket peat: measurement and variability, Hydrol. Process., 17, 12271237, 2003.

Holden, J., Chapman, P. J., and Labadz, J. C.: Artificial drainage of peatlands: hydrological and hydrochemical process and wetland restoration, Prog. Phys. Geog., 28, 95-123, 2004.

Holden, J., Evans, M. G., Burt, T. P., and Horton, M. M.: Impact of land drainage on peatland hydrology, J. Environ. Qual., 35, 1764-1778, 2006.

Holden, J., Gascoign, M., and Bosanko, N. R.: Erosion and natural revegetation associated with surface land drains in upland peatlands, Earth Surf. Proc. Land., 32, 1547-1557, 2007.

Holden, J., Kirkby, M. J., Lane, S. N., Milledge, D. G., Brookes, C. J., Holden, V., and Mcdonald, A. T.: Overland flow velocity and roughness properties in peatlands, Water Resour. Res., 44, W06415, doi:10.1029/2007WR006052, 2008.
Lane, S., Brookes, C. J., Kirkby, A. J., and Holden, J.: A networkindex based version of TOPMODEL for use with high-resolution digital topographic data, Hydrol. Process., 18, 191-201, 2004.

Letts, M. G., Roulet, N. T., Comer, N. T., Skarupa, M. R., and Verseghy, D. L.: Parametrization of Peatland Hydraulic Properties for the Canadian Land Surface Scheme, Atmos. Ocean, 38, 141-160, 2000.

Milne, R. and Brown, T. A.: Carbon in the Vegetation and Soils of Great Britain, J. Environ. Manage., 49, 413-433, 1997.

Pearce, A. J. and Rowe, L. K.: Rainfall interception in a multistoried, evergreen mixed forest: estimates using Gash's analytical model, J. Hydrol., 49, 147-163, 1981.

Price, J. S.: Role and character of seasonal peat soil deformation on the hydrology of undisturbed and cutover peatlands, Water Resour. Res., 39, 1241, doi:10.1029/2002WR001302, 2003.

Ramchunder, S. J., Brown, L. E., and Holden, J.: Environmental effects of drainage, drain-blocking and prescribed vegetation burning in UK upland peatlands, Prog. Phys. Geog., 33, 49-79, 2009.

Robinson, M.: Changes in catchment runoff following drainage and afforestation, J. Hydrol., 86, 71-84, 1986.

Saltelli, A., Tarantola, S., Campolongo, F., and Ratto, C.: Sensitivity analysis in practice: a guide to assessing scientific models, John Wiley \& Sons Inc., Chichester, 219 pp., 2004.

Shampine, L. F. and Reichelt, M. W.: The MATLAB ODE Suite, SIAM J. Sci. Stat. Comp., 18, 1-22, 1997.

Shampine, L. F., Reichelt, M. W., and Kierzenka, J. A.: Solving Index-1 DAEs in MATLAB and Simulink, SIAM Rev., 41, 538$552,1999$.

Shantz, M. A. and Price, J. S.: Characterization of surface storage and runoff patterns following peatland restoration, Quebec, Canada, Hydrol. Process., 20, 3799-3814, 2006.

Stewart, A. J. and Lance, A. N.: Moor-draining: A review of impacts on land use, J. Environ. Manage., 17, 81-99, 1983.

Stewart, A. J. and Lance, A. N.: Effects of moor-draining on the hydrology and vegetation of northern Pennine blanket bog, J. Appl. Ecol., 28, 1105-1117, 1991.

Wallage, Z. E., Holden, J., and McDonald, A. T.: Drain blocking: An effective treatment for reducing dissolved organic carbon loss and water discolouration in a drained peatland, Sci. Total Environ., 367, 811-821, 2006.

Wheater, H. S., Reynolds, B., McIntyre, N., Marshall, M., Jackson, B., Frogbrook, Z., Solloway, I., Francis, O., and Chell, J.: Impacts of land management on flood risk: FRMRC RPA2 at Pontbren, FRMRC Final Report and UFMO, 2008.

Wilson, L., Wilson, J., Holden, J., Johnstone, I., Armstrong, A., and Morris, M.: Recovery of water table in Welsh blanket bog after drain blocking: Discharge rates, time scales and the influence of local conditions, J. Hydrol., 391, 311-386, 2010.

Worrall, F., Armstrong, A., and Holden, J.: Short-term impact of peat drain-blocking on water colour, dissolved organic carbon concentration, and water table depth, J. Hydrol., 337, 315-325, 2007a.

Worrall, F., Gibson, H. S., and Burt, T. P.: Modelling the impact of drainage and drain-blocking on dissolved organic carbon release from peatlands, J. Hydrol., 338, 15-27, 2007 b. 